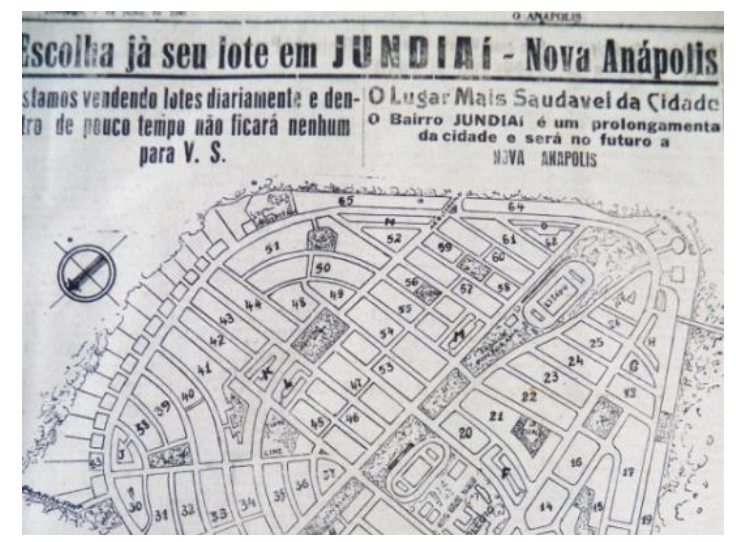

\title{
Discursos imobiliários e o reforço da imagem urbana no bairro Jundiaí, em Anápolis, GO
}

\author{
Real estate speeches and urban image reinforcement \\ in Jundiaí neighborhood, Anápolis, GO
}

\author{
Ana Laura Lopes Cabral 1 \\ ORCID: https://orcid.org/0000-0003-3078-4136 \\ Milena d'Ayala Valva2 \\ ORCID: https://orcid.org/0000-0003-3735-2328
}

Resumo: O artigo propõe debater o espaço urbano e sua relação com a imagem urbana, tendo como sujeito de pesquisa o bairro Jundiaí, em Anápolis (GO), priorizando uma abordagem teórica interdisciplinar. $\mathrm{O}$ bairro em questão tem recebido crescentes investimentos imobiliários desde a valorização consequente da implantação do parque ambiental Ipiranga, e nota-se a tentativa de estabelecerem-se novos hábitos. Recorre-se ao conceito de city marketing, tendo em vista que as cidades são tratadas como mercadorias no cenário da produção e reprodução de espaço no capitalismo. Para alcançar os objetivos, é necessária a aproximação com os discursos utilizados pela publicidade dos empreendimentos imobiliários do bairro, assim como as principais ferramentas utilizadas para veiculá-los, atingindo seu público-alvo.

Palavras-chave: Imagem urbana; Discursos imobiliários; Bairro Jundiaí; Anápolis.

Abstract: The article proposes debating urban space and its relation with the urban image, having as research subject the Jundiaí neighborhood, in Anápolis (GO), prioritizing an interdisciplinary theoretical approach. The neighborhood in question has received increasing real estate investments since the consequent appreciation of the implementation of Ipiranga environmental park, and there is an attempt to establish new habits. The concept of city marketing is used, considering that cities are treated as commodities in the scenario of the production and reproduction of space in capitalism. To achieve the objectives, it's necessary to approach the discourses used by the advertising of neighborhood real estate developments, as well as the main tools used to convey them, reaching their target audience.

Keywords: Urban image; Real estate advertising, Jundiaí neighborhood, Anápolis.

1 Universidade Estadual de Goiás (UEG). Graduada em Arquitetura e Urbanismo (dez./2017). Discente no Mestrado Interdisciplinar em Territórios e Expressões Culturais no Cerrado (TECCER) da UEG (mar./2018-fev/2020). Bolsista CAPES. E-mail: anarqurb20@gmail.com.

2 Universidade Estadual de Goiás (UEG). Docente no Mestrado Interdisciplinar (TECCER) e no curso de Arquitetura e Urbanismo da UEG. Doutorado em Projeto, Espaço e Cultura pela Universidade de São Paulo (2011) com estágio no IUAV-Veneza (2008-2009). E-mail: midayala@gmail.com. 


\begin{abstract}
"Você sabe melhor do que ninguém, sábio Kublai, que jamais se deve confundir uma cidade com o discurso que a descreve. Contudo, existe uma ligação entre eles. [...] A mentira não está no discurso, mas nas coisas." (CALVINO, 1990, p. 27)
\end{abstract}

\title{
1. Introdução
}

No mundo contemporâneo, cada vez mais globalizado e caracterizado por um capital informacional e cognitivo (RIBEIRO, 2012, p. 61), o espaço urbano tem recebido sempre mais a atenção dos seus agentes produtores, que priorizam as decisões que dizem respeito à localização de novos empreendimentos, conjuntos habitacionais, equipamentos de infraestrutura urbana, etc. Com isso, torna-se valiosa a criação ou fortalecimento da imagem associada aos lugares e à própria cidade, como caminho necessário ao seu reconhecimento e posteriores investimentos urbanos, associando-se, na maioria das vezes, representantes do poder público e da iniciativa privada, além de agentes publicitários e outros grupos dominantes, para a execução de planos estratégicos que correspondem aos interesses destes segmentos sociais. Conforme Vainer,

Se durante largo período o debate acerca da questão urbana remetia, entre outros, a temas como crescimento desordenado, reprodução da força de trabalho, equipamentos de consumo coletivo, movimentos sociais urbanos, racionalização do uso do solo, a nova questão urbana teria, agora, como nexo central a problemática da competitividade urbana. (VAINER, 2000, p. 76) [grifos do autor]

Ao prosseguir, o autor pontua essa competitividade como um dos pilares do que Harvey denomina de "empresariamento da gestão urbana", a partir do qual a cidade é comparada a uma empresa, além de mercadoria em si (Harvey, 1996, in VAINER, 2000, p. 85). Nos grandes centros metropolitanos, primeiro palco da maioria dos fenômenos urbanos, é fácil identificar a ocorrência desta mercadorização da cidade, verificada especialmente a partir de 1990 (SÁNCHEZ, 2001, p. 33). Mas também nas cidades pequenas e, especialmente, nas médias é possível encontrar exemplos cada vez mais nítidos da reprodução deste processo, dentro das escalas adequadas a cada contexto urbano. Conforme Pereira,

Com as novas lógicas de estruturação urbana nas cidades médias a partir da década de 1980, é possível observar que o setor de comércio e serviços tem desempenhado importante função na orientação das novas estratégias de produção do espaço urbano, sendo também evidente a atuação, em certos casos, da indústria e do mercado imobiliário. (PEREIRA, 2013, p. 2) 
Envolvendo esta lógica, existe uma produção discursiva e midiática, que colabora para a propagação de um "mercado de modelos com alternativas capazes de oferecer outros valores e projetos ideais de cidade" (VAINER, 2000, p. 78), sobre o qual desejamos tratar com mais ênfase aqui. Acredita-se que essa força midiática influencia diretamente as relações socioeconômicas em escala global, mas também local, conferindo maior ou menor valor a determinados espaços-mercadoria, concordando com Steinberger, “É no próprio espaço da mídia que se estabelece o valor social de uma imagem de mundo como informação e como resposta, isto é, qual valor a sociedade irá consignar a essa imagem de mundo numa situação de troca" (STEINBERGER, 2005, p. 19).

$\mathrm{O}$ questionamento que fazemos aqui objetiva atravessar os discursos existentes sobre o espaço urbano do bairro Jundiaí, indo ao encontro do que apresenta Souza (2013, p. 160): "Perscrutar representações sócio-espaciais pressupõe interrogar os discursos e as palavras no contexto dos discursos, adentrando os 'mundos da vida' e examinando o senso comum e suas contradições". O autor propõe ainda "descer das alturas que permitem a perspectiva 'voo de pássaro' e o tratamento em escala global, nacional, regional e mesmo macro e mesolocal, chegando à escala da habitação ou do pequeno assentamento humano" (idem).

Os discursos sobre o espaço urbano tem sido cada vez mais apelativos para enfatizar a imagem que desejam transmitir, e vice-versa. Conforme Lefebvre,
A imagem e o discurso remetem um ao outro. A imagem traz um campo de significações (de significantes) muito vasto, sempre incerto e múltiplo, que só o discurso pode dizer (mudar em significado), enquanto ele mesmo flutua no espaço. Ele parece apoiar-se na imagem, e é ela que precisa de apoio; mas o próprio discurso não sabe mais sobre o que se apoiar e se aplicar. (LEFEBVRE, 1991, p. 128-129)

Tanto o discurso como a imagem apoiam-se nas representações, que ocupam o imaginário coletivo, ressignificam espaços e lhes atribuem valores diferentes. De acordo com Arantes Neto, os habitantes da cidade "compartilham certas representações em suas leituras do espaço urbano, atribuindo significações diferenciadas a lugares de poder, estruturando-os em graus de importância e centralidade" (ARANTES NETO, 2000, p. 103). Estas representações compartilhadas é que produzem o convencimento, primeiro no campo das ideias, depois, nas relações socioespaciais de forma mais concreta.

Fábio Duarte afirma que, "a vivência de um espaço se dá na relação entre o uso que se faz dele e a carga simbólica que lhe é impregnada", logo, se dá tanto na 
subjetividade como na dimensão do espaço construído, propriamente. O autor ainda continua: "estes elementos (objeto, uso, carga simbólica), alimentam-se e transformamse constantemente; ou seja, tanto uma intervenção física pode alterar as possibilidades de uso de um espaço, quanto uma construção simbólica pode tentar induzir determinados usos" (DUARTE, 2007, p. 194). O papel da publicidade estaria aliada a esta construção simbólica, com vias à indução de imagens e de usos.

Diante disso, este trabalho pretende investigar o tema proposto partindo da cidade de Anápolis, especialmente do bairro Jundiaí, acreditando que este seja um recorte interessante e atual para compreendermos o fenômeno do city marketing, partindo da análise dos discursos imobiliários e dos demais elementos articulados à consolidação da imagem de um lugar ideal para se investir, morar e desenvolver outras atividades cotidianas. Além de analisar estes instrumentos midiáticos, adotou-se como caminho metodológico o exercício da caminhada urbana, visando a aproximação com o espaço dito "real", para além das imagens consensuais já conhecidas e divulgadas. Permeando a apresentação dos fatos e opiniões sobre o lugar, priorizou-se o debate teórico interdisciplinar, acreditando que esta é uma postura interessante para discutir questões da cidade contemporânea.

\section{A reprodução do city marketing em Anápolis}

O fenômeno do city marketing começou a ser notado inicialmente em grandes centros urbanos, e gradualmente tem ocorrido também em escalas menores, mais próximas à realidade urbana em estudo. Conforme Sánchez, "a existência de um mercado de cidades, como um fenômeno recente, mostra a importância cada vez maior do espaço no capitalismo [...] evidencia a produção global do espaço social”. (SÁNCHEZ, 2001, p. 33). Esta produção da qual fala a autora, tende ainda a gerar certa padronização das escolhas arquitetônicas e urbanísticas, que reproduzem imagens de espaços ideais, amparados por discursos propagandísticos, como as demais mercadorias. Ao falar da publicidade, Jacques afirma que

O que já foi pensado enquanto opinião pública, debate público, acabou resumido a mera pesquisa de mercado, cujo principal objetivo é atuar como uma eficiente fábrica de consensos. $\mathrm{Na}$ atual sociedade do espetáculo não há, de fato, lugar para qualquer tipo de espaço dissensual ou contra-hegemônico, o que resulta no empobrecimento da própria experiência urbana, em particular da experiência sensível e corporal das cidades - aquilo que vai além da pura visualidade imagética. $\mathrm{O}$ 
consenso busca também uma homogeneização das sensibilidades, das diferentes formas de "partilha do sensível". (JACQUES, 2009, s/p.)

Essa "fábrica de consensos" tem como finalidade convencer o consumidor a comprar seu produto que, neste caso, se trata do próprio espaço da cidade, tendo, por isso, que ser bem representado. Conforme Steinberger, "construir discursivamente representações sociais do mundo é também produzi-lo socialmente" (STEINBERGER, 2005, p. 31), por isso percebemos que é crescente o investimento em ferramentas discursivas aliadas às visuais para fortalecer imagens e comercializar a mercadoria urbana.

Como exemplos disso, Anápolis foi apresentada em matéria do Globo Repórter como "uma das cidades da região [Centro-Oeste] líder em felicidade futura. Terra de oportunidades (...)" (G1 Globo, 2013). Em 2017, um portal de notícias local apresentou a cidade a partir de uma série de imagens retratando seus espaços públicos, estruturas de transportes e outros registros acompanhados de legendas positivas, como: "Revistas Veja, Exame e IstoÉ Dinheiro destacaram que Anápolis é uma das melhores cidades do interior do Brasil na atualidade. O otimismo traduz a autoestima da população. Anápolis, cidade da hora e da vez. Do agora e do futuro. Do sonho e da oportunidade!” (Anápolis Global, 2017).

Aliada à matéria citada, intitulada "Anápolis é feliz cidade", encontram-se outras no mesmo portal: "Anápolis Trevo do Brasil" (set./2017), "Motivos para investir em Anápolis" (out./2017) e "Anápolis é o eixo do maior corredor de riquezas do Brasil" (jun./2018). Outra recente menção à cidade foi numa matéria do portal G1, que tem por título "Já pensou em morar na cidade mais feliz do Centro-Oeste? Conheça Anápolis" (G1 Globo/GO, 2019), seguida de uma imagem com visão panorâmica da cidade, ampla e iluminada, contrastando com o céu noturno (Figura 1). 


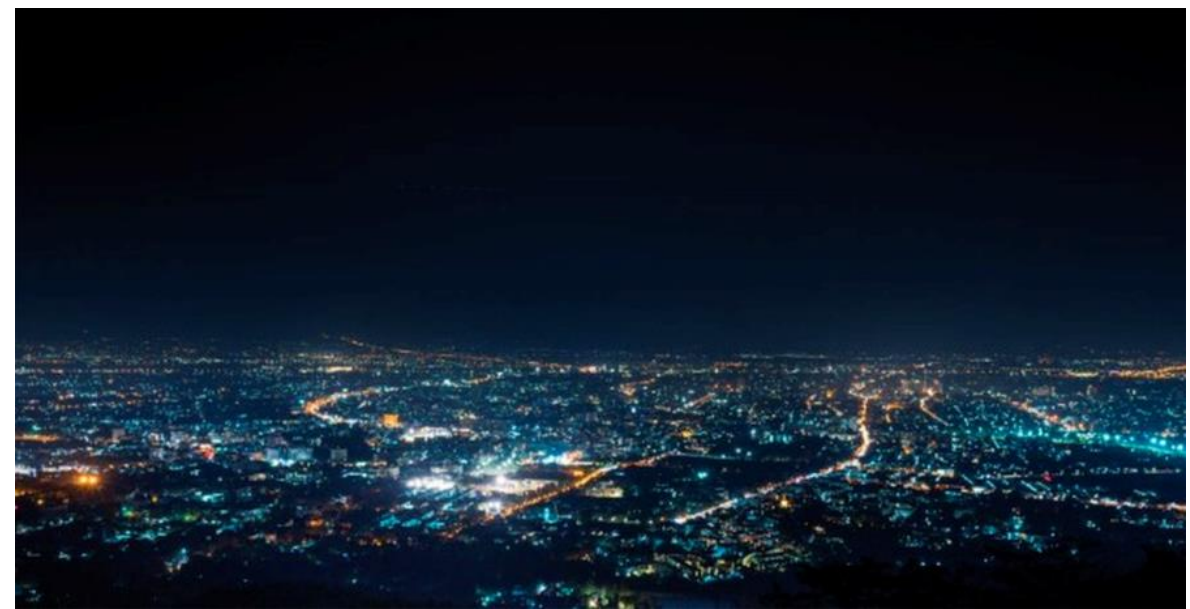

Figura 1. "Anápolis, a cidade mais feliz do Centro-Oeste”. Fonte: Gl Globo/GO.

Faria, relendo outros autores, coloca que "a 'disputa pelo poder de representar o espaço se configura como a disputa política para influir em sua produção material e simbólica, isto é, a disputa em torno da legitimidade de evocar uma dada imagem que o demarque, inscrevendo-lhe sentidos que sejam socialmente reconhecidos"' (Bourdieu e Novais, in FARIA, 2012, s/p.). Acreditando que o consumidor-alvo desta "cidade-objeto de luxo" (VAINER, 2000, p. 78) sejam os que detêm maior capital, concordamos novamente com Steinberger (2005, p. 200), quando diz que "as elites consomem hoje mais bens simbólicos do que bens materiais".

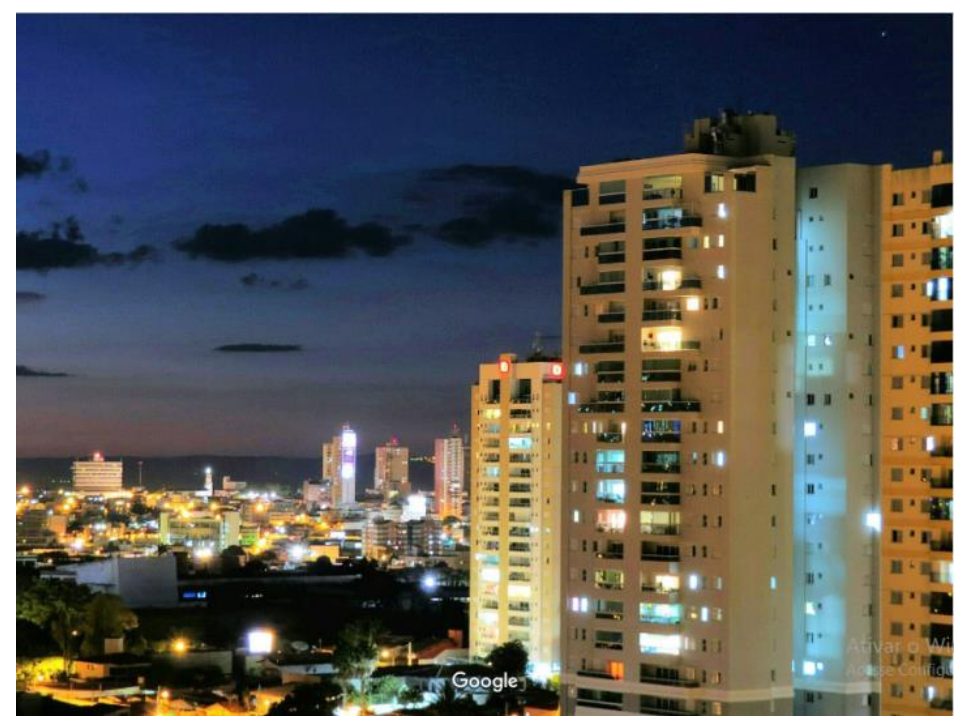

Figura 2. Imagem de referência ao pesquisar por "bairro Jundiaí" no Google Maps. Fonte: Google Maps. Foto atribuída a Pedro Henrique, out. 2017.

Nesta imagem do Google Maps, por exemplo, nota-se a intenção de conferir certa grandeza ao lugar, tendo adotado como referência um ângulo que possibilita uma visão mais verticalizada do bairro Jundiaí, apesar desta não ser dominante na paisagem, mas representar apenas uma região específica do bairro. A iluminação das ruas e no interior 
dos edifícios contrasta com o céu noturno, dando a impressão da dinamicidade do lugar apesar do horário do registro. Sabe-se, conforme apresentaremos adiante, que existem outras áreas do bairro que se comportam de forma bem diversa, mas esta seria a imagemsíntese que domina o imaginário social, interferindo nas relações sócio-espaciais. Concluímos com Célia Ferraz de Souza que,

Portanto, o espaço é uma representação coletiva onde existe uma relação direta entre o mesmo e o comportamento social. Mas a representação social é basicamente construída pelo imaginário que uma coletividade elabora de si mesmo, a partir do estabelecimento de papeis e das posições sociais, exprime ou impõe crenças comuns e constrói códigos através de modelos formadores de ideia ou opiniões. Assim sendo, o imaginário social é uma das forças reguladoras da sociedade. (SOUZA, 1996, p. 210)

Quanto ao bairro Jundiaí, o recorte espacial delimitado neste estudo, acredita-se que ele sintetiza o debate das representações imagéticas e discursivas que colocamos aqui, na medida em que transparece uma imagem consensual e homogênea (Figura 2), apesar de ser um espaço heterogêneo, que apresenta suas complexidades quando percorrido com mais atenção e sensibilidade, possibilitando enxergar as contradições, "os não-ditos, aquilo que está por traz" (DAOU, 2012, p. 157) mas convivendo no mesmo espaço.

\section{Novas formas, novos padrões, novos hábitos no Jundiaí: um ideal de habitar?}

Antes de adentrar à realidade do tempo presente, vale mencionar que o bairro Jundiaí foi o primeiro bairro planejado em Anápolis, cujo desenho, do engenheiro e urbanista João Alves Toledo3, data de 1943 e apresenta referências do modelo cidadejardim4 (Figura 3). Apesar de não ter sido apropriado como previa o planejamento, perdendo boa parte de seus espaços públicos originais para o loteamento privativo, o bairro ainda sustenta uma imagem superior em relação aos demais, como um lugar acessível, saudável, e que oferece variados usos (residencial, comercial, institucional, de serviços, entretenimento, etc.), como aspectos que qualificam a vida urbana e conferem um caráter de centralidade ao bairro.

\footnotetext{
3 Superintendente geral da Companhia Serviços de Engenharia, de São Paulo, contratada, na época, pela Prefeitura de Anápolis para diversos serviços de melhoramento urbano, entre eles, o projeto do bairro Jundiaí (jornal O Anápolis, 17/10/1943).

4 Conceito idealizado na Inglaterra por Ebenezer Howard (1850-1928), cujo principal objetivo é combinar as características do campo e da cidade na busca de uma cidade ideal. Foi adotado no Brasil a partir de bairros paulistas, especialmente o Jardim América (1917) e o City Lapa (1919).
} 


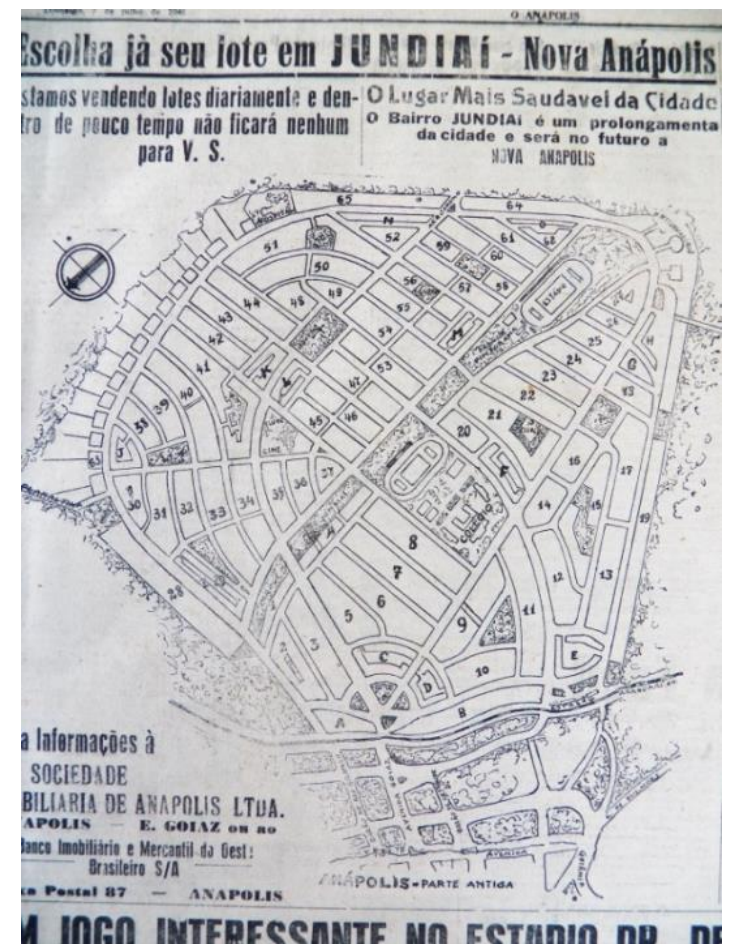

Figura 3. Foto do jornal $O$ Anápolis com propaganda do empreendimento, julho de 1946.

Fonte: Acervo do Museu Histórico Alderico Borges de Carvalho.

Desde 2010, com a implantação do Parque Ambiental Ipiranga sobre uma área que estava subutilizada, o seu entorno tem passado por alterações significativas devido ao processo de valorização, o que fomentou uma leva de investimentos imobiliários, com cada vez mais pavimentos. Hoje, esses novos empreendimentos lançados tem adotado como discursos não apenas a sua localização no dito "melhor bairro da cidade", mas estratégias que remetem a "uma nova forma de viver" (Figura 4), que aparecem nos vídeos produzidos e editados, acompanhados de efeitos sonoros e músicas que realçam o "espetáculo" da mercadoria ofertada, além de sorrisos e registros de momentos que representam a felicidade como consequência de tal aquisição.

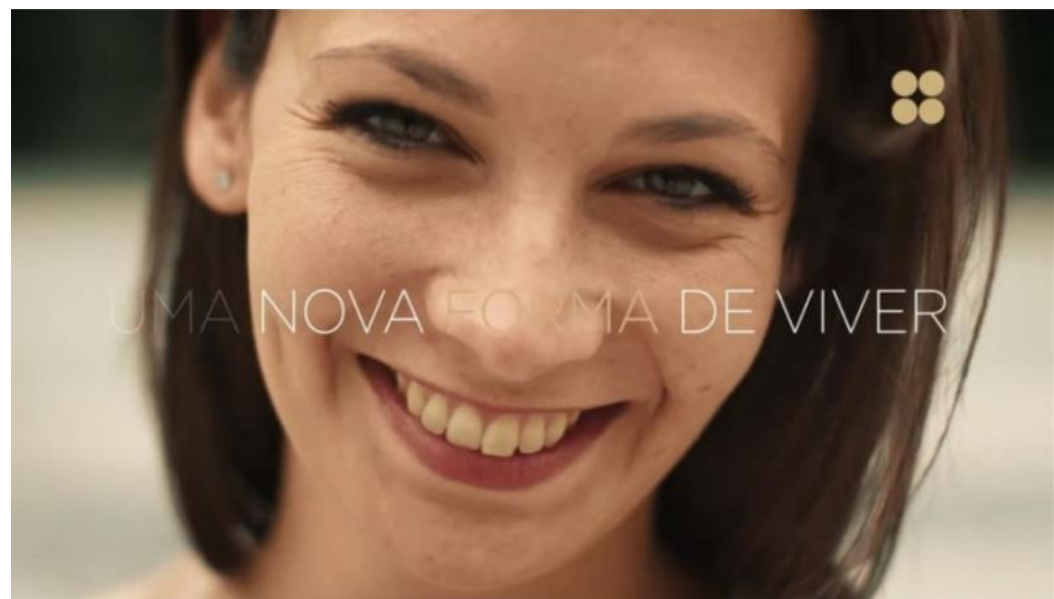

Figura 4. Captura de tela em anúncio do Forma Opus Jundiaí. Fonte: OPUS IC, 2019b. 
Quanto à aparência, a estetização da paisagem é reproduzida no acabamento das fachadas dos edifícios, no jogo de transparências, no uso de revestimentos que simulam diversos materiais, nas novas soluções de desenho, no paisagismo e ainda no tratamento das imagens de apresentação dos projetos, seguindo padrões de escritórios de arquitetura que atendem a grandes centros metropolitanos, o que reforça a representação que convence sobre o espaço ideal (Figuras 5 e 6). Conforme Jacques,

Os atuais projetos urbanos contemporâneos são realizados no mundo inteiro segundo uma mesma estratégia: homogeneizadora, espetacular e consensual. Estes projetos buscam transformar os espaços públicos em cenários, espaços desencarnados, fachadas sem corpo: pura imagem publicitária. (JACQUES, 2009, s/p.)

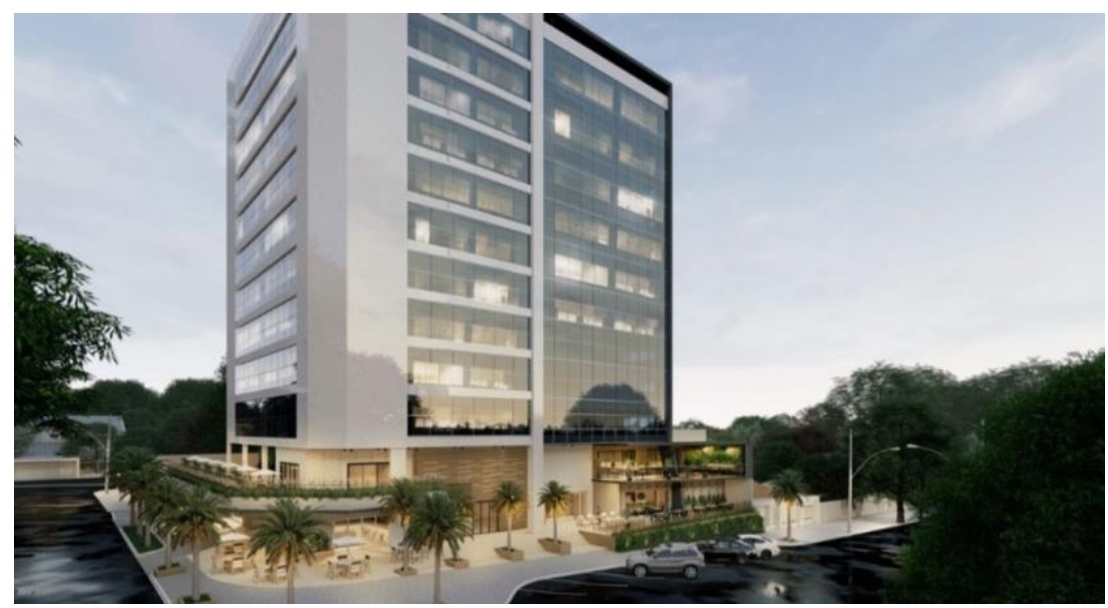

Figura 5. Imagem do projeto do edifício multifuncional São Francisco Business Tower.

Fonte: SFBT.

Aproveita-se muito também do ideal de natureza e lazer associado à presença do parque ambiental, com anúncios como: "Aqui a natureza está ao seu lado, dia e noite" (EMISA, 2019b), ou ainda,

O melhor projeto, com o espaço, o conforto e a privacidade de uma casa, chega à melhor localização do melhor bairro de Anápolis. Jundiaí, o bairro mais nobre de Anápolis, ganha o conceito mais exclusivo da Opus. Um projeto contemporâneo, exclusivo e absolutamente incomparável. Todo o aconchego de um Casa Opus em frente ao parque mais charmoso de Anápolis - Parque Ipiranga - 45 mil $\mathbf{m}^{2}$ de natureza e lazer a seus pés. Fácil acesso às principais avenidas da cidade. (OPUS IC, 2019a) [grifo nosso] 

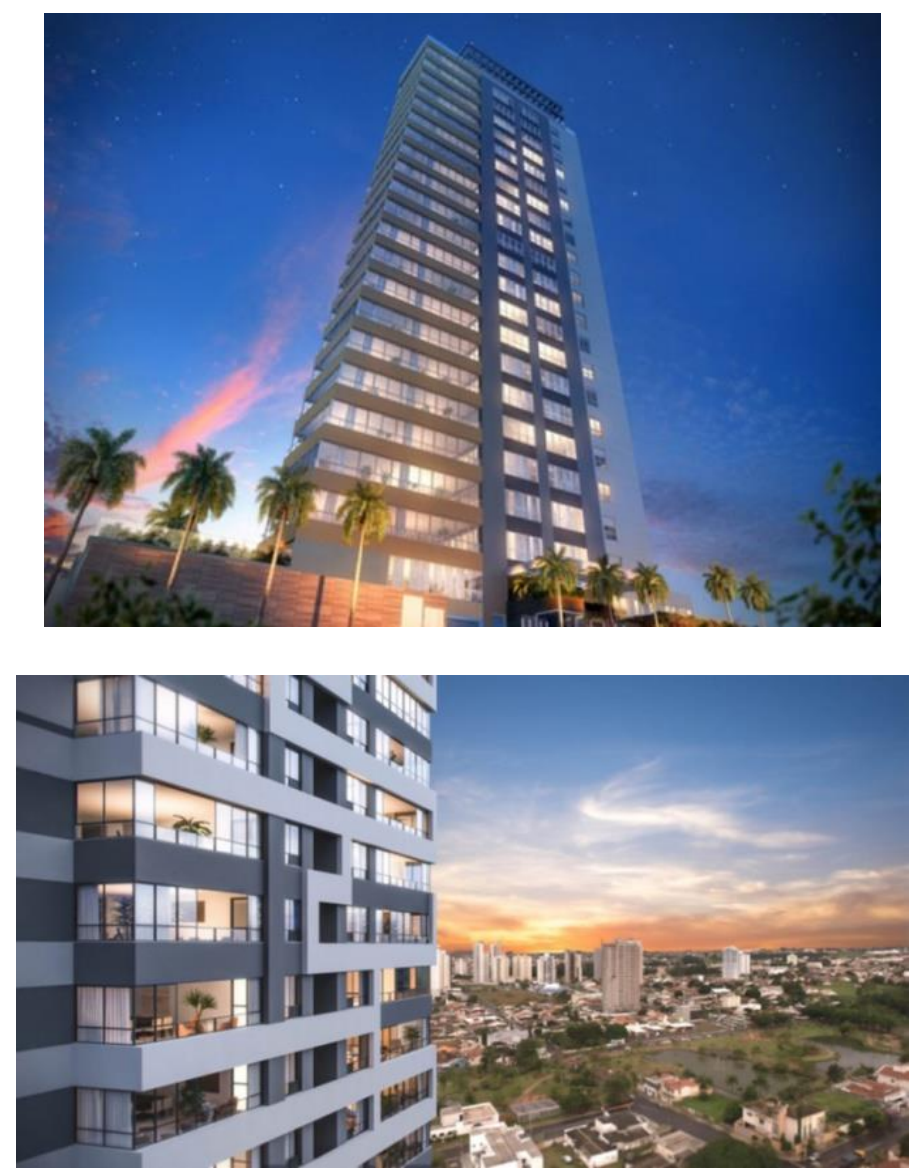

Figura 6. Imagens dos projetos do Casa Opus Ipiranga e Forma Opus Jundiaí. Fonte: OPUS IC, 2019.

Os novos hábitos que estes edifícios pretendem assumir ou ressignificar passam ainda por ideais de beleza e saúde da vida contemporânea que tem valorizado os equipamentos esportivos e de estética corporal. Portanto, os espaços privativos destinados a academias, spas e entretenimento fazem parte do programa arquitetônico contemporâneo como se seguissem a uma bula (Figura 7). Conforme Arantes Neto, "novas configurações socioculturais e novos estilos de vida passam a participar do jogo político de identidades, tendendo a produzir repertórios simbólicos, demandas e reivindicações que terão efeito sobre a vida social e, particularmente, sobre a agenda política local" (ARANTES NETO, 2000, p. 156). 


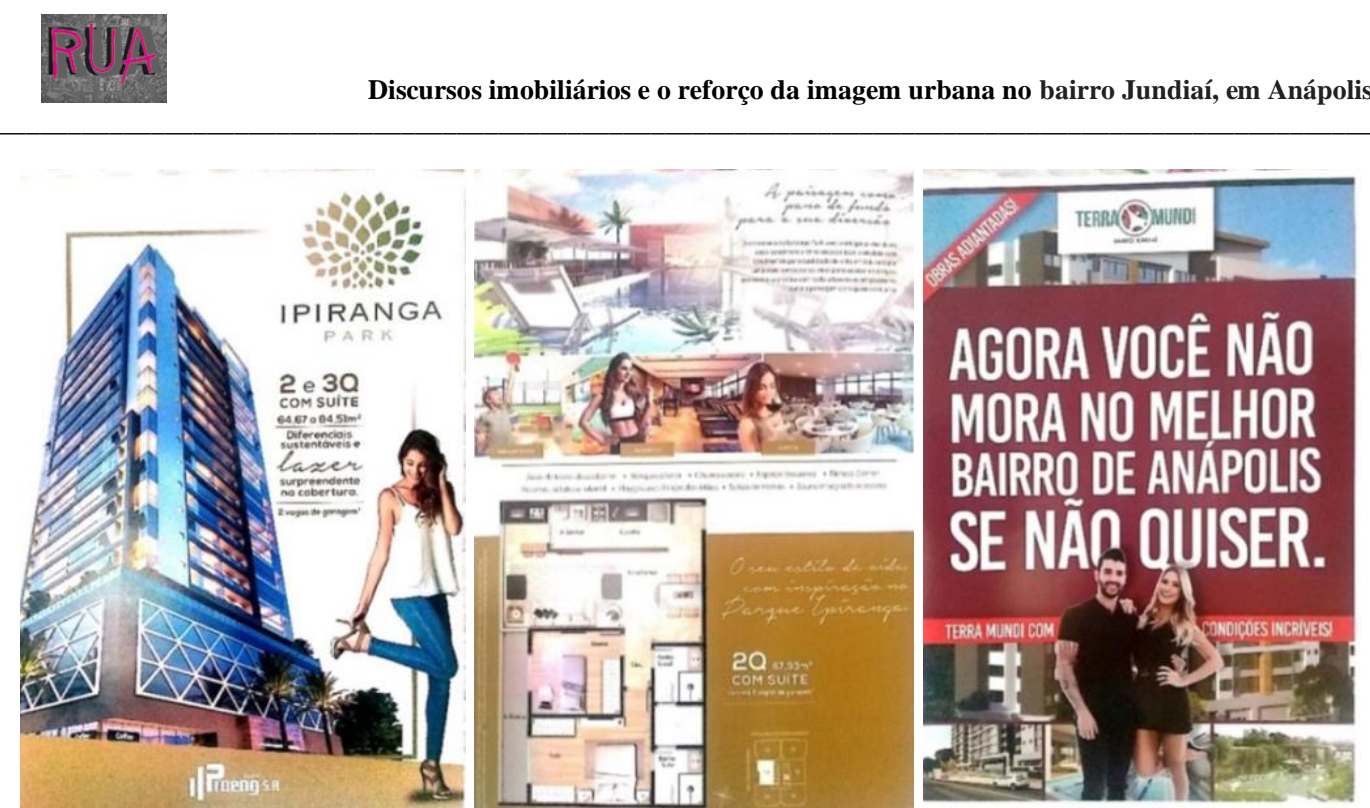

Figura 7. Panfletos do Ipiranga Park e do Terra Mundi.

Fonte: digitalização de material impresso recebido na rua.

Atendendo à demanda das classes para as quais são realizados, os empreendimentos milionários têm proposto e vendido um número cada vez maior de vagas privativas de estacionamento, correspondendo aos modos de vida desta parcela da população, caracterizada pela escolha do automóvel particular como principal meio de deslocamento intraurbano (Figura 8).

\section{Apartamento com 4 Quartos à Venda, $335 \mathrm{~m}^{2}$ por $\mathbf{R} \$ 2.999 .000$}

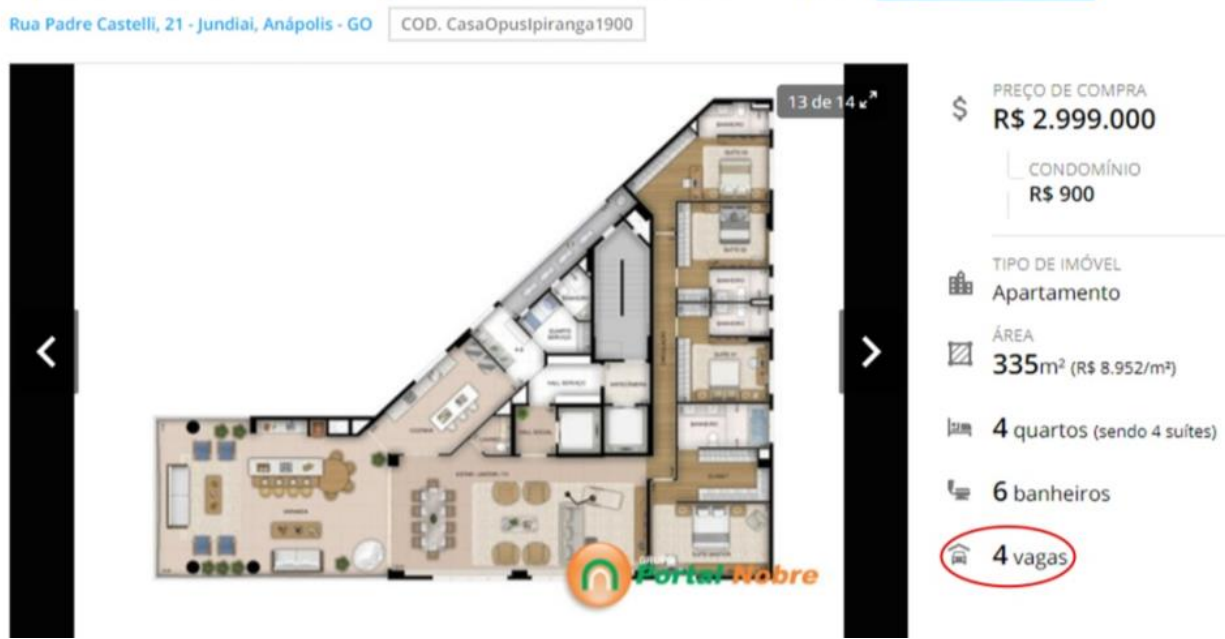

Figura 8. Imagem de anúncio do empreendimento Casa Opus Ipiranga. Fonte: IMOVEL WEB, 2019.

Vimos, no anúncio ilustrado acima, um único apartamento com quatro vagas de garagem exclusivas. Sobre isso, Sposito pontua que está relacionado também à criação de uma nova centralidade: 
[...] as redes de distribuição comercial e de serviços, ao instalarem esses grandes equipamentos, não somente respondem aos interesses das novas zonas residenciais e aos hábitos de uso cada vez mais frequentes do automóvel, mas, sobretudo, propõem e criam uma nova centralidade. Para fazê-lo, incluem no projeto imobiliário e na estratégia locacional elementos capazes de materializar objetivamente essa centralidade (acesso ao sistema de circulação, vastas áreas de estacionamento, oferta concentrada de produtos e serviços etc.) e de maneira subjetiva (nova imagem urbana, marca do modernismo etc.)" (SPOSITO, 2010, p. 207).

Portanto, este anseio por estabelecer novas formas de viver, tão presente nos anúncios imobiliários do Jundiaí, faz parte da estratégia subjetiva de ressignificar a imagem do bairro para atrair ainda mais investimentos e valorização para a área. Esse fenômeno geralmente é acompanhado por uma diferenciação de valores imobiliários, inclusive de impostos sobre a terra urbana em determinadas áreas da cidade, o que geralmente reproduz a segregação socioespacial. De acordo com Arantes Neto,

Essa competição, que é motivada pela expectativa de bons negócios e de um saldo econômico positivo para as cidades e seus habitantes (em termos de investimentos permanentes na infraestrutura urbana), é o principal elemento do processo pelo qual algumas delas constituem imagens diferenciadas de lugar e procuram elevar, por intermédio do capital simbólico, sua posição na competição mundial por visibilidade e por investimentos. [...] Essa acumulação cria sítios de densidade informacional e tecnológica diferenciada e estabelece hierarquias entre países, cidades e, sobretudo, entre zonas dentro de cidades, pelas quais se reordenam e estratificam-se os usos do solo urbano que produzem, em última instância, valor imobiliário diferenciado. (ARANTES NETO, 2000, p. 155)

É comum encontrarmos anúncios como: "Escolher sempre a melhor localização é um cuidado que para a Opus não tem preço, tem um valor" (OPUS IC, 2019a). E deste valor, nem todos podem usufruir; bem poucos, aliás, se considerarmos que a maioria da população não tem condições de adquirir um apartamento que custe cerca de três milhões de reais (Figura 8). Portanto, não mentem os anúncios que falam sobre a exclusividade e o privilégio de seus clientes: "Exclusividade é morar em um condomínio vertical de alto padrão, com localização privilegiada e uma vista única para o parque mais bonito da cidade: O Parque Ipiranga.” (EMISA, 2019a). Quanto a isso, Vainer afirma que,

Em todos os níveis, tanto do ponto de vista concreto (infra-estruturas, subsídios, favores fiscais, apoios institucionais e financeiros de todos os tipos) quanto do ponto de vista da imagem, não resta dúvida: a mercadoria-cidade tem um público consumidor muito específico e qualificado. (VAINER, 2000, p. 82) 
Logo, esta dita novidade no habitar não chega a todos, mas é destinada a uma parcela específica e qualificada da população, que possui capital suficiente para escolher seu lugar na cidade além de possuir maior "controle dos tempos de deslocamento" (VILLAÇA, 2001) graças à disponibilidade de automóvel(is) na garagem. Pallasmaa (2011, p. 67) afirma que "A arquitetura reflete, materializa e torna eternas as ideias e imagens da vida ideal. As edificações e cidades nos permitem estruturar, entender e lembrar o fluxo amorfo da realidade e, em última análise, reconhecer e nos lembrar quem somos”. No entanto, o Jundiaí não pertence só a este público para o qual destinam-se os novos empreendimentos, mas abriga uma população heterogênea, contradizendo os discursos dominantes.

\section{O discurso e sua relação com o lugar; o lugar e sua relação com o discurso}

"O olhar percorre as ruas como se fossem páginas escritas: a cidade diz tudo o que você deve pensar, faz você repetir o discurso, e, quando você acredita estar visitando Tamara, não faz nada além de registrar os nomes com os quais ela define a si própria e todas as suas partes. Como é realmente a cidade sob esse carregado invólucro de símbolos, o que contém e o que esconde, ao se sair de Tamara é impossível saber." (CALVINO, 1990, p. 9)

Estas imagens do bairro "sofisticado e autossuficiente" (Premiere, 2019), "uma cidade em Anápolis", melhor localização da cidade, etc., que encontramos nos anúncios publicitários, são exemplos das imagens-síntese que reforçam o imaginário acerca do bairro Jundiaí, e que induzem a busca por estabelecimento de padrões para construir e habitar este espaço, mas que não o representam em sua totalidade. Conforme Ribeiro, trata-se de "uma seleção que escolhe lugares para o imaginário urbano e que tende a substituir o discurso do habitante pelo da imprensa: 'A sociedade quer isto ou aquilo', 'A sociedade quer paz'." (RIBEIRO, 2011, p. 29).

Mas, apesar de não serem representações tão fiéis, "as palavras qualificam o espaço" (SEGAUD, 2016, p. 104), influenciando, em certa medida, as dinâmicas econômicas e socioespaciais. Muitos destes discursos sobre o bairro referem-se na verdade ao entorno imediato do parque Ipiranga, reconhecido como o "cartão-postal de Anápolis" (Portal 6, 2017), ou o "coração do Jundiaí” (SFBT, 2019), como se este fosse um sujeito independente do corpo urbano em geral. Sobre isso, Pereira tece a seguinte crítica: 
Assim, mesmo alguns dos comerciantes referindo-se a um sentido de "coração do bairro", que pode levar a um entendimento de que o bairro é uma unidade autônoma da cidade, isso é preciso ser entendido, nos termos que sugerimos, como uma centralidade e um espaço de referência situado e subordinado ao próprio movimento da cidade e à hierarquia subjacente a ele. (PEREIRA, 2018, p. 177).

Concordando então com Pereira, chamar o bairro Jundiaí de "autossuficiente" soa presunção, tendo em vista que possui relações de interdependência com o centro e outros bairros e regiões da cidade, seja na oferta de equipamentos públicos, serviços urbanos e, principalmente, abastecimento de mercadorias e mão de obra. Mas retomando a ideia da "fábrica de consensos" de Jacques (2009, s/p.), devemos considerar a força quase manipuladora dos discursos midiáticos para construir realidades como estratégia subjetiva para criar e fortalecer lugares. Segundo Steinberger,

A mídia desempenha um papel, nessa perspectiva, de agente social que pressiona, através da formação da opinião pública, para que os fatos gerem os efeitos desejados pelos que dela se utilizam. Atua, portanto, como instrumento de práticas político-ideológicas. (STEINBERGER, 2005, p. 210).

Tais práticas atingem o domínio do espaço, já que este é socialmente construído e alterado, especialmente quando se investem cada vez mais em ferramentas para comunicar estas ideias e discursos consensuais, como as produções audiovisuais que promovem a cidade e seus novos empreendimentos, veiculados através da televisão e dos diversos dispositivos móveis que permitem o acesso à internet e às redes sociais. Ribeiro nos aponta ainda que "existem desafios relacionados à preservação da palavra diante do poder de convencimento da imagem e, sobretudo, das várias linguagens que prometem representar o espaço com perfeição" (RIBEIRO, 2011, p. 24). Em Ferrara, encontramos o desafio da própria realidade. Segundo a autora,

Toda representação é uma imagem, um simulacro do mundo a partir de um sistema de signos, ou seja, em última ou em primeira instância, toda representação é gesto que codifica o universo, daí se infere que o objeto mais presente e, ao mesmo tempo, mais exigente de todo processo de comunicação é o próprio universo, o próprio real. (FERRARA, 1997, p. 7)

Por fim, acreditamos que questionar os discursos, as leituras do espaço, é um caminho alternativo para se interpretar este universo "real", também contestável. Segaud (2016, p. 106) coloca que "é preciso considerar que os lugares existem não em abstrato, mas de maneira concreta, material e simbólica, especialmente verbal [...]. Assim, ler o espaço permite uma construção, uma interpretação da sociedade, a descrição de um 
verdadeiro estado social". E a partir destas interpretações, poderíamos então investigar os contrassensos, os avessos do que está colocado como regra.

\section{Consolidando uma imagem? Em busca de considerações finais}

Conhecer as leituras que dominam o imaginário acerca do bairro Jundiá, possibilita uma análise um pouco menos ingênua ao desvelarmos o espaço experimentado pelos sentidos, o que amplia esse entendimento para além do campo visual. "E como experienciá-la senão através de nosso corpo? A cidade só se desdobra para nós quando caminhamos por ela. Pela implicação espacial e temporal de nosso movimento é possível descobri-la como pluralidade, diversidade, superabundância." (OLIVEIRA, 2012, p. 224). Esta heterogeneidade pode ser encontrada quando abandonamos a cegueira própria do universo das imagens hegemônicas e deparamo-nos com outras realidades (Figura 9).

Portanto, a imagem de uma cidade não é somente aquela formada pela sua topografia e processos econômicos e sociais. Ela se forma também de outras imagens que compõem seu passado e o presente de sonhos. Sempre existe algo de obscuro no mundo das imagens, que tornam encantadas uma cidade. Por isso sempre nos perdemos um pouco quando deixamos que a subjetividade oriente a interpretação de um lugar. (OSTERMANN, 1996, p. 162)

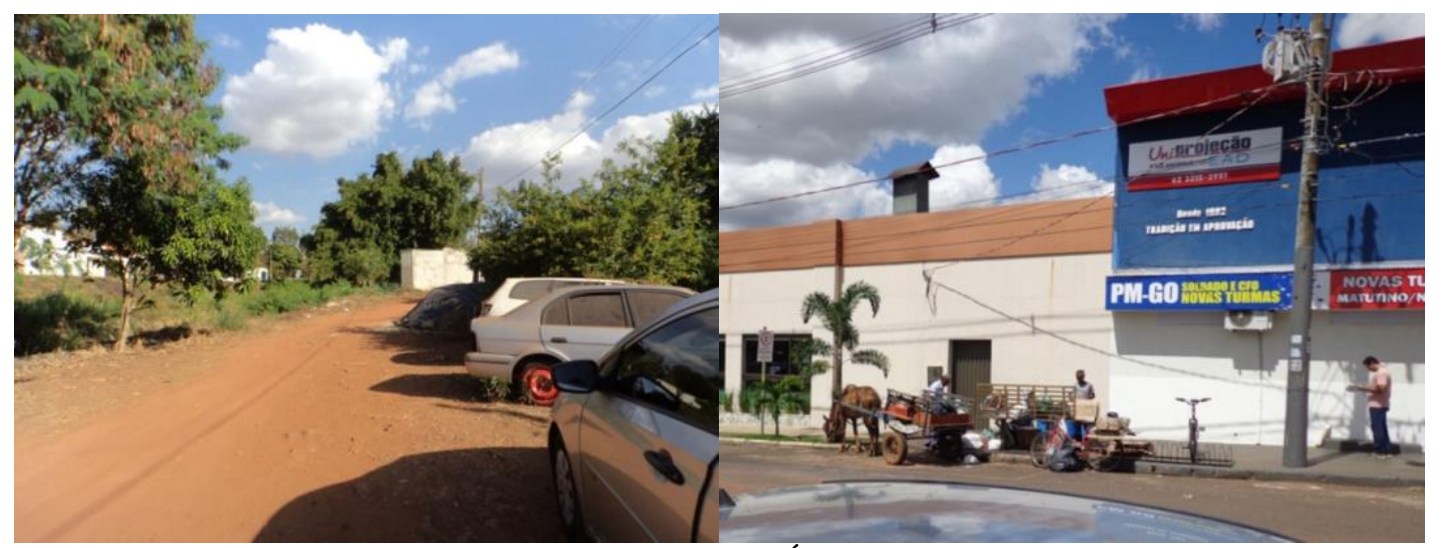

Figura 9. Rua não asfaltada às margens do córrego Água Fria (à esquerda); carroceiro e catador em avenida (à direita), representando a diversidade socioespacial do bairro Jundiaí. Fonte: registros de campo.

Compreendendo este "perder-se" na interpretação do lugar como um processo bastante pessoal, desvelado pela experiência sensível da cidade, consideramos a importância de abrir espaço para outras leituras (Figura 10). Isto porque o habitar apresentado pelos novos empreendimentos não contemplam uma visão democrática do lugar, concordando que "tais imagens consensuais de espaços aparentemente destituídos 
de seus conflitos inerentes, dos desacordos e dos desentendimentos, são imagens de espaços apolíticos." (JACQUES, 2009, p. p. 7).

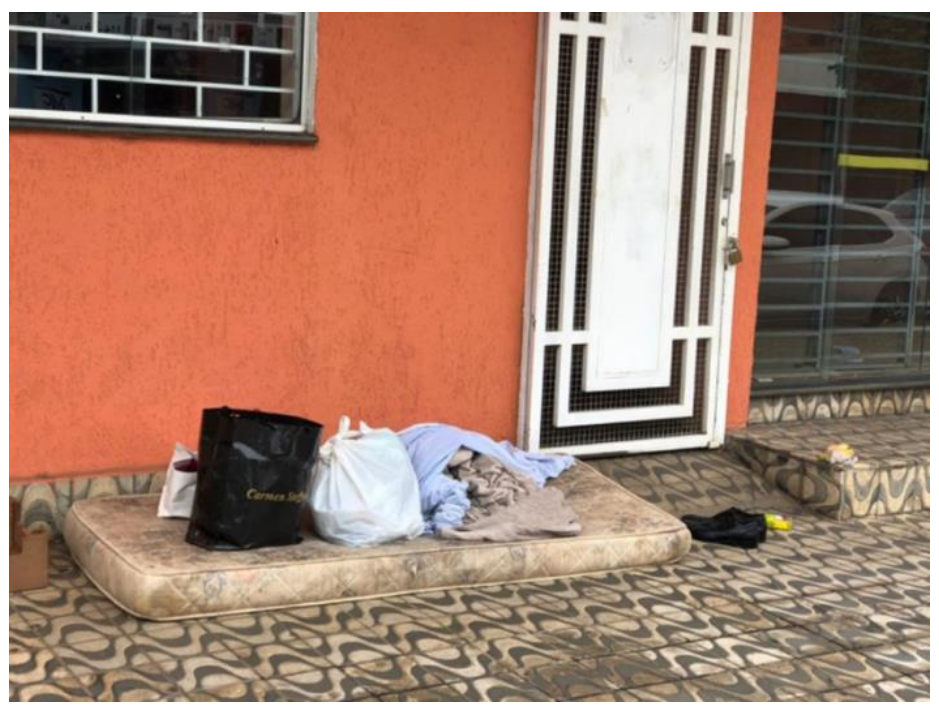

Figura 10. O habitar informal: pertences sob marquise na avenida Mato Grosso.

Fonte: registros de campo.

O poder de fascínio da imagem, pode inclusive alterar a realidade dos fatos, condizer com ela ou distorcê-la. Conforme Pitanguy, (1996, p. 127) “As imagens da cidade, visíveis e invisíveis, construindo e desconstruindo o real, estabelecem sua plasticidade, sempre aberta aos nossos olhares". Imagens no plural justamente porque não existe apenas uma forma de imaginar um lugar, mas uma composição de imagens "visíveis e invisíveis", mais ou menos presentes no imaginário social e na memória dos cidadãos, mais ou menos percebidas na vivência do espaço urbano, superpostas, de acordo com Ostermann.

A cidade é um discurso e esse discurso é na verdade uma linguagem: um livro de pedras construído, permitindo a formação de uma imagem. Para entender a imagem de uma cidade a partir do conceito de imaginação, podemos dizer que ela é construída da superposição de imagens gerais e singulares, objetivas e subjetivas, quer dizer, de imagens percebidas e imagens imaginadas. (OSTERMANN, 1996, p. 161)

Concordamos também com Jacques, quando diz que estas imagens que vendem espaços como um espetáculo urbano, encobrem uma realidade bem mais complexa. A autora coloca que as relações entre a imagem urbana e o espaço público da cidade "passam hoje inevitavelmente pelo processo de espetacularização urbana contemporânea, que é um dos maiores responsáveis tanto pela negação dos conflitos e dissensos no espaço público contemporâneo quanto pelo empobrecimento das experiências corporais nestes espaços" (JACQUES, 2009, p. 4). Jacques alerta ainda quanto à "negação, eliminação ou 
ocultamento da vitalidade dos espaços mais populares das cidades, que buscam se tornar midiáticas e espetaculares" (idem).

Esta espetacularização urbana, conforme apresenta a autora, esvazia as experiências sócio-espaciais de seu sentido, de sua vitalidade. Pallasmaa acrescenta que,

O bombardeio incessante do imaginário não relacionado leva a um esvaziamento gradual do conteúdo emocional das imagens. As imagens são convertidas em mercadorias infinitas fabricadas para postergar o tédio; os próprios seres humanos são mercantilizados, se consumindo de modo indiferente, sem ter a coragem ou mesmo a possibilidade de confrontar sua própria realidade existencial. Somos feitos para viver em um mundo de sonhos fabricado. (PALLASMAA, 2011, p. 32-33)

Paralelamente, em Ribeiro (2012, p. 30) temos que "existe, de fato, uma vitalidade social extraordinária sistematicamente recusada por discursos, mapas e imagens", e é este habitar vivo, democrático, baseado na experiência do cotidiano e da caminhada pela cidade, que se deseja continuar investigando.

\section{Referências}

ANÁPOLIS GLOBAL. Anápolis é feliz cidade, 2017. Disponível em: <http://anapolisglobal.com.br/anapolis-e-feliz-cidade/>. Acesso em: 01/07/2019.

ARANTES NETO, A. A. Paisagens paulistanas: transformações do espaço público. Campinas: Editora da Unicamp; São Paulo: Imprensa Oficial, 2000. 190 p.

CALVINO, I. As cidades invisíveis. Tradução de Diogo Mainardi. São Paulo: Companhia das Letras, 1990. 152 p.

DAOU, A. M. Sobre os avessos da história e dos espaços urbanos no Brasil. In: ANDRADE, R. de.; TERRA, C. (orgs.). Avesso da paisagem: percepção artístico-urbana e dimensão socioespacial. Rio de Janeiro: Rio Book's, 2012. p. 157-166.

DUARTE, F. Cidade, modos de usar: um ensaio sobre Curitiba. In: FERRARA, L. D`A.; DUARTE, F.; CAETANO, K. E. (orgs.). Curitiba: do modelo à modelagem. São Paulo: Annablume; Curitiba: Champagnat, 2007. p. 171-234.

EMISA INCORPORADORA. Belvedere du Parc, 2019a. Disponível em: $<$ https://construtoraemisa.com.br/empreendimentos/belvedere-du-parc/>. Acesso em: 02/07/2019.

EMISA INCORPORADORA. Mirantes do Vale, 2019b. Disponível em: <https://construtoraemisa.com.br/empreendimentos/mirantes-do-vale/>. Acesso em: 03/07/2019.

FARIA, J. R. V. de. Discursos e impactos em grandes projetos urbanos: estudo de caso sobre a Cidade Administrativa Presidente Tancredo Neves. In: OLIVEIRA, F. L.; CARDOSO, A. L.; COSTA, H. S. M; VAINER, C. B. (Orgs.). Grandes Projetos Metropolitanos: Rio de Janeiro e Belo Horizonte. 1ed. Rio de Janeiro: Letra Capital, 2012. p. 216-231.

FERRARA, L. D’A. Leitura sem palavras. São Paulo: Ática, 1997. 72 p. 
G1 GLOBO. Pesquisa do IPEA aponta o Centro-Oeste como a região mais positiva com relação ao amanhã, 2013. Disponível em: <http://g1.globo.com/globoreporter/noticia/2013/11/pesquisa-do-ipea-aponta-o-centro-oeste-como-regiao-maispositiva-com-relacao-ao-amanha.html>. Acesso em: 04/07/2019.

G1 GLOBO/GO. Já pensou em morar na cidade mais feliz do Centro-Oeste? Conheça Anápolis. Por Faculdade Metropolitana de Anápolis - FAMA, 2019. Disponível em: <https://g1.globo.com/go/goias/especial-publicitario/faculdademetropolitana-de-anapolis-fama/noticia/2019/01/28/ja-pensou-em-morar-na-cidademais-feliz-do-centro-oeste-conheca-anapolis.ghtml>. Acesso em: 04/07/2019.

IMOVEL WEB, Imobiliária. Apartamento, Setor Jundiai (4 Quartos, 5 Banheiros, 4 Vagas). Casa Opus Ipiranga, 2019. Disponível em: $<$ https://www.imovelweb.com.br/propriedades/apartamento-setor-jundiai-4-quartos-5banheiros>. Acesso em: 05/07/2019.

JACQUES, P. B. Notas sobre espaço público e imagens da cidade. Arquitextos (São Paulo), 2009. Disponível em: <http://www.vitruvius.com.br/revistas/read/arquitextos/10.110/41>. Acesso em: jul. 2019.

LEFEBVRE, H. A vida cotidiana no mundo moderno. São Paulo: Editora Ática, 1991. $216 \mathrm{p}$.

OLIVEIRA, B. O direito da cidade e o avesso da arte. In: ANDRADE, R. de.; TERRA, C. (orgs.). Avesso da paisagem: percepção artístico-urbana e dimensão socioespacial. Rio de Janeiro: Rio Book's, 2012. p. 201-228.

OPUS IC, Incorporadora. Casa Opus Ipiranga, 2019a. Disponível em: <http://opusic.com.br/imovel/casa-opus-ipiranga/>. Acesso em: 06/07/2019.

OPUS IC, Incorporadora. Forma Opus Jundiaí, 2019b. Disponível em: <http://opusic.com.br/imovel/forma-opus-jundiai/>. Acesso em: 07/07/2019.

OSTERMANN, E. A. Imagem urbana: Percepção e Devaneio. In: MACHADO, D. B. P.; VASCONCELlOS, E. M. de. (orgs.). Cidade e Imaginação. Rio de Janeiro: UFRJ/FAU/PROURB, 1996. p. 157-164.

PALLASMAA, J. Os olhos da pele: a arquitetura e os sentidos. Porto Alegre: Bookman, 2011. $76 \mathrm{p}$.

PEREIRA, C. S. S. Comércio e serviços: a centralidade urbana na cidade média de Juazeiro do Norte/CE. In: IV Colóquio Internacional sobre o comércio e cidade: uma relação de origem. Uberlândia, 2013, p. 1-19.

PITANGUY, Y. Cidade, projetos e cotidiano. In: MACHADO, D. B. P.; VASCONCELLOS, E. M. de. (orgs.). Cidade e Imaginação. Rio de Janeiro: UFRJ/FAU/PROURB, 1996. p. 126-129.

PORTAL 6. Cartão postal de Anápolis, parque Ipiranga está sendo revitalizado, 2017. Disponível em: <https://portal6.com.br/2017/12/22/cartao-postal-de-anapolisparque-ipiranga-esta-sendo-revitalizado/> . Acesso em: 08/07/2019.

PREMIERE, Imóveis. Bairros em Anápolis: um guia com as características dos principais setores da cidade, 2019. Disponível em: <http://www.premiereimoveis.imb.br/blog/bairros-em-anapolis-caracteristicas-dosprincipais-setores-da-cidade>. Acesso em: 09/07/2019. 
RIBEIRO, A. C. T. Territórios da sociedade: por uma cartografia da ação. In: SILVA, C. A. da (org.). Território e ação social: sentidos da apropriação urbana. Rio de Janeiro: Lamparina, 2011. p. 16-30.

RIBEIRO, A. C. T. Homes lentos, opacidades e rugosidades. REDOBRA. Salvador, PRONEM/UFBA, n. 9, 2012. p. 58-71.

SÁNCHEZ, F. O city marketing de Curitiba: Cultura e comunicação na construção da imagem urbana. In: OLIVEIRA, L. de.; RIO, V. del. Percepção ambiental: a experiência brasileira. São Paulo: Studio Nobel, 1999. 2 ed. p. 83-96.

SÁNCHEZ, F. A reinvenção das cidades na virada de século: agentes, estratégias e escalas de ação política. Revista Sociol. Polít., Curitiba, 2001. v.16. p. 31-49.

SBTC. São Francisco Business Tower. Euro Construções, 2019. Disponível em: <https://nocoracaodojundiai.com.br/>. Acesso em: 10/07/2019.

SEGAUD, M. Antropologia do espaço: habitar, fundar, distribuir, transformar. São Paulo: Edições SESC São Paulo, 2016. 312 p.

SOUZA, C. F. de. Entre a cidade do desejo e a cidade do possível: um plano de melhoramentos para Porto Alegre em 1914. In: MACHADO, D. B. P.; VASCONCELlOS, E. M. de. (orgs.). Cidade e Imaginação. Rio de Janeiro: UFRJ/FAU/PROURB, 1996. p. 208-222.

SOUZA, M. L. de. A cidade, a palavra e o poder: práticas, imaginários e discursos heterônomos e autônomos na produção do espaço urbano. In: CARLOS, A. F. A.; SOUZA, M. L. de; SPOSITO, M. E. B. (orgs.). A produção do espaço urbano: agentes e processos, escalas e desafios. São Paulo: Contexto, 2013. p.147-166.

SPOSITO, M. E. B. Multi(poli)centralidade urbana. In: SPOSITO, E. S.; SANT'ANNA NETO, J. L. (Orgs.). Uma Geografia em Movimento. São Paulo: Expressão Popular, 2010. p. 199-228.

STEINBERGER, M. B. Discursos geopolíticos da mídia: jornalismo e imaginário internacional na América Latina. São Paulo: EDUC; Fapesp; Cortez, 2005. 312 p.

VAINER, C. Pátria, empresa e mercadoria: notas sobre a estratégia discursiva do Planejamento Estratégico Urbano. In: ARANTES, O.; VAINER, C.; e MARICATO, E. A cidade do pensamento único. Petrópolis: Vozes, 2000. p. 75-104.

VILLAÇA, F. Espaço intra-urbano no Brasil. São Paulo: FAPESP, 2001. 392 p.

Data de Recebimento: 14/01/2020

Data de Aprovação: 23/04/2020 


\section{Para citar essa obra:}

CABRAL, Ana Laura Lopes e VALVA, Milena D’Ayala. Discursos imobiliários e o reforço da imagem urbana no bairro Jundiaí, em Anápolis, GO. In: RUA [online]. Volume 26, número 1 - Ahead of print - e-ISSN 2179-9911 -jun./2020. Consultada no Portal Labeurb - Revista do Laboratório de Estudos Urbanos do Núcleo de Desenvolvimento da Criatividade.

http://www.labeurb.unicamp.br/rua/

Capa: Lixão de Juazeiro/ BA foto de Glauco Umbelino. Disponível em: https://flic.kr/p/36EB8S

Laboratório de Estudos Urbanos - LABEURB

Núcleo de Desenvolvimento da Criatividade - NUDECRI

Universidade Estadual de Campinas - UNICAMP

http://www.labeurb.unicamp.br/

Endereço:

LABEURB - LABORATÓRIO DE ESTUDOS URBANOS

UNICAMP/COCEN / NUDECRI

CAIXA POSTAL 6166

Campinas/SP - Brasil

CEP 13083-892

Fone/ Fax: (19) 3521-7900

Contato: http://www.labeurb.unicamp.br/contato 